\title{
Intervention Guidelines on Teaching Social and Motor Skills in Kindergarten
}

\author{
Pedro Gil Madrona*, José Roldán Iniesta, Ana Isabel García Espinosa, Javier Sánchez Sánchez \\ Facultad de Educación de Albacete, Universidad de Castilla La Mancha, Spain \\ *Corresponding author: Pedro.Gil@uclm.es
}

Received November 20, 2014; Revised December 15, 2014; Accepted December 25, 2014

\begin{abstract}
Too often, the motor activities for small children in kindergarten resemble or are presented as free play, or, these tasks are inspired by the desire of adults to keep children busy and happy. The focus of a motor programme in Physical Education for kindergarten children is the learning of children. A motor program well built and well presented, offers much more than just the children the opportunity to "vent" or "enjoy". Actually a quality program of Physical Education should facilitate the total development of the child in the affective-social, cognitive and motor areas. Children are able to learn to be responsible for their own actions if they are taught systematically behavior the sooner, the better. In fact you have to plan the motor and social improvement through movement experiences and games. The instructions below give some ideas of how to teach movement and social in the field of Physical Education in Early Childhood Education skills.
\end{abstract}

Keywords: social skills, kindergarten, physical, education, movement

Cite This Article: Pedro Gil Madrona, José Roldán Iniesta, Ana Isabel García Espinosa, and Javier Sánchez Sánchez, "Intervention Guidelines on Teaching Social and Motor Skills in Kindergarten." American Journal of Sports Science and Medicine, vol. 2, no. 6A (2014): 9-12. doi: 10.12691/ajssm-2-6A-3.

\section{Introduction}

The fundamental movement skills are the foundation for future motor capabilities. In 2002, the National Association for Sport and Physical Education (NASPE) developed a "national movement guidelines" (a national guidelines in the USA with tips for sports), [1] stating that "all children from birth to age 5 years should participate in daily physical activity that promotes health-related skills and movement. These tips or "guidelines" underscore the importance of the activities or physical activity experiences that promote the development of motor skills in young children. In particular, the advice or guideline number 3 of this writing, recommends, "Pre-schoolers should develop competence in skills (abilities) of motion which are built in blocks to reach capacities of more complex movement."

Certainly, from the perspective of the development of motor skills, abilities and basic motor skills are extremely important to achieve in the future learning specific skills and the development of movement abilities of young children. In fact, until the child has not developed these skills, he will not be able to apply them into sports, games, etc. Clark and Metcalfe 2002 in their "Mountain of motor development" [2] point that the goal of the development of fundamental motor skills is to "build a motor set sufficiently varied that will enable future learning of actions that will let be flexible and adapted to different contexts motion ".

The basic motor skills consist of motor capabilities such as walking, rolling, crawling, running and jumping, which means the body's movement through space. The control capabilities such as grasping and throwing objects include the object manipulation with hands or feet. These abilities are considered basic in motion. For example, a child who is not totally able to run or kick something will not be able to apply these skills successfully for example in football. Actually, some studies about motor development show that getting a very basic motor skills development during childhood through physical education according to age is very important so that in the future the boy successfully participate in sports, games and physical activities.

On the other hand physical education, even in early childhood education can not only deal with children to develop the psychomotor skills, but also can provide psychological and social benefits through the development of personal and social responsibility and appropriate social behaviour that requires the society in which it is immersed. However, the social growth of young children is not an automatic result of participation in physical activity. A systematic and organized appropriate educational practice to improve the efficient development of positive social skills is required. To help children develop responsible behaviour and social skills, physical education teachers can design appropriate activities that foster the physical and social development. These activities can be games that claim that children show specific behaviours and skills. Once children have achieved these behaviours and skills in the field of physical education, physical education teachers can deal with the study and see how this learning can be transferable to the classroom and other environments as the playground. Certainly social growth is not an automatic result of participation in physical 
activity and therefore must be deliberately fostered (Gil Madrona et al., 2008) [3].

The purpose of this paper is twofold. On the one hand to review the importance of the development of motor and social skills related to learning and child development and on the other hand, provide guidance for physical education teachers to develop specific practices that integrate these motor and social skills and ways of working in kindergartens, nursery schools and classrooms of children in nursery and primary schools.

\section{Teaching Guidelines for Successful Learning of Motor Skills in Young Children}

One of the most important guidelines for teaching movement is providing varied range of activities, original, with variations and repetition until mastery of skill. Then increase the challenge. Practicing a movement session provides many opportunities for children to exercise a new skill. Once you have mastered the skill, it is important to change the activity and present a more difficult skill, because this helps children and minimizes frustration or boredom. Another guideline in planning the lessons is that activities should be challenging but no distressing or annoying, and should not change the task, although the practice implying new activities until the child is successful at least 75 percent of the time. A third guideline would provide feedback to children. Regarding to this, it is essential to strive to provide at least four positive comments among all the comments and one negative.

When the teacher is developing a motor program, a prerequisite and key is the design of what he wants children learn. It involves, therefore, teacher plans what children are feeling, thinking and learning when they move skilfully. So a quality motor program must address the curricular objectives in three domains: cognitive, motor and affective. Regarding the affective domain (feelings or emotions), movement activities provide excellent opportunities for children to develop positive feelings about themselves and others. Movement activities also provide wonderful opportunities to teach a variety of cognitive concepts, knowledge and perception. Since children enjoy moving and when they move with full satisfaction children take part in motor activities because they are happy, joyful, happy and also attentive and therefore prepared to the learning of cognitive concepts.

In this sense the curricular objectives of a motor movement program for children in the affective area would include: strengthening the image so that children feel themselves, develop positive self-image and selfesteem, develop self-motivation to become independent learners, develop social skills and develop games cheerfully. The objectives in the motor program or kindergarten movement in the cognitive area would include: learn to communicate, learn the basic rules of the games, learn to recognize objects, colours, sizes, textures, and shapes and learn to identify parts of body. And in relation to the objectives of the program for children in the motor area: learning the basic and generic motor skills, develop physical fitness related to health, the acquisition and mastery of the body schema.
The teachers must know some guidelines that are suitable in order to get the motor practices adapt to the development of preschool children. For that reason we consider appropriate to highlight the guidelines stated by "The National Association for Sport and Physical Education USA" which emphasisesfive assumptions: Children aged 3, 4 and 5 are different from the children of primary school. Children learn through their interaction with their environment. Teachers of children are their guides. Children learn and develop themselves in an integrated and comprehensive manner. There must be careful planning to improve the experience of movement through experience and play.

To this end we will present the guidelines for the teacher to build a quality motor program for children in kindergarten.

- Firstly it is required an assessment of motor skills and interests of their students, as well as the facilities and equipment available in the context of intervention.

- Then the teacher must address to develop a curriculum that includes writing curriculum objectives he wants children to achieve during the course of his intervention proposal.

- The next step will be develop lessons or sessions for the development of the plan, program or lesson plan of movement and in that way, help children achieve these curricular objectives.

- Create a welcoming environment is another important consideration by the teacher in kindergarten.

- Of utmost importance will also be establishing routines for each of the lessons: warm-up or entertaining activities, introducing the concepts of the lesson, activities to practice motor skills, the space distribution of motor circuits and relaxation, or a summary of the lesson. Sometimes it will be necessary to use certain music to liven the lesson and the activities so that the music will be used to start and stop the activity. Children can learn quickly they can start an activity when listening the music start and going to stop the activity when the music stops.

- The teacher should establish clear boundaries that convey to children that they can and cannot do.

- The teacher should propose open-ended activities that allow experimentation and exploration.

- In relation to the planning of the lesson or session the estimated duration is about 50 minutes with animated exercises, where activities are sometimes accompanied with music. It will be necessary that the teacher explains and guides motor activities to finally students become relaxed or warm- down, with a summary of the exercises. It is advisable to stop any motor activity before the interest of the children start to decrease. In this way, the child will be eager to play and participate again in these activities in the following classes.

\section{Guidelines for Teaching Social Skills Learning in Physical Education in Small Children}

Social growth is not an automatic result of participation in physical activity, but it must be intentionally fostered. Physical Education, as it has become clear throughout the text, can not only help children develop psychomotor 
skills, but also can provide psychological benefits through the development of personal and social responsibility and appropriate social behaviour. However, the social growth of young children is not an automatic result of participation in physical activity. The curricula require an organized and systematic teaching to improve the efficient development of positive social skills. In order to help children to develop responsible behaviours and social skills, physical education teachers can design appropriate activities for the physical development such as games that require children to demonstrate specific behaviours and skills activities. Once children have demonstrated these behaviours and skills in the field of physical education, physical education teachers can discuss how it can also be applied in the classroom and in other settings like the playground (McWayne, Fantuzzo, \& McDermott, (2004). [4].

The purpose of this section is:

1) Review the importance of social skills related to learning and responsible behaviour improvement in children's learning.

2) Provide guidance for physical education teachers to develop lesson plans that integrate these skills and behaviours in a kindergarten in physical education.

McClelland and Morrison (2003) [5] identified certain social behaviours that influence school children's learning and performance. This includes listening and following instructions, participate adequately in groups, staying on task, and the organization of work materials. These behaviours are known as "social skills related to learning" and are directly related to the success and adjustment of school-age children. Cooper and Farran (1991) [6] specify that social skills related to learning increase children's cooperation, responsibility, independence and selfregulation skills in school.

In order to teach children socially responsible behaviours to help them adjust to the school environment, Rairigh and Townsend (2001) [7] specify that students must first develop their personal responsibilities, such as the ability to make decisions based on a task. Secondly, students should be able to use self-direction and reflection in order to develop social responsibility and make positive contributions to the rest of the students. Socially responsible behaviours, such as respect, cooperation and appropriate participation in groups, are especially important for children to use when interacting with mates and teachers in the classroom. The instructional model Hellison (2003), [8] the teaching of personal and social responsibility, focuses on teaching students to be personally and socially responsible. The model has been used to build a sense of responsibility for personal development, well-being and learning, as well as to others inside and outside the room-gym. The model of teaching personal and social responsibility helps students to develop social skills that can improve their academic performance. By combining social learning skills with the teaching of personal and social responsibility, students can learn skills to be more successful in the learning environment. What better place to learn these skills than in kindergarten?

Below we present the teaching levels in the social skills model related to the learning of personal and social responsibility Hallison (2003).

The social skills levels related to the learning-teaching of the personal and social responsibility are cumulative, as in the original model of teaching personal and social responsibility. Therefore, the behaviours must be taught sequentially, and each level must be explained, practiced, evaluated and reviewed. For example, children first must learn to take personal responsibility in their learning environment. Once they understand what their personal responsibility is, they will be able to transfer the social responsibility. Thus, the level one teaches children basic personal responsibility to listen and follow the teacher's instructions. Children, in level one of behaviours, listen to the teacher, looking at his eyes when the teacher is talking to them, raising their hands to ask for permission to ask or answer to the teacher, and follow the instructions of the teacher to participate in physical activities.

In level two children are taught to develop social responsibility in order to participate appropriately in group activities. Children at level two show appropriate behaviours of mutual aid, cooperation with the group members, and they are willing to take turns while maintaining their own personal responsibility to listen and follow instructions from the teacher to participate in the activities of the group.

In level three the most advanced children are taught the personal and social responsibility to concentrate on the task. The children at level 3 show an appropriate behaviour trying to finish the task independently or through cooperation with other members of the group. Therefore they are also able to complete the task with or without teacher supervision. This helps children to understand that it is their responsibility to do their best in order to complete the task requested by the teacher, if they are working independently or with others in the field of physical education.

The fourth level teaches children to be personally and socially responsible when they have to work in groups developing the activities. Children at level 4 show appropriate behaviour taking care of the mates and sharing everything with them. In this level students must follow safety rules for the use of the equipments, as well as the replacement of equipment after the activity is carried out. Children understand they are responsible of their own safety and the others by using the equipment correctly and following the rules.

The fifth level teaches children the personal and social responsibilities can be transferred to other areas of the real life, such as their classroom. At this level, children learn that the levels of responsibility are not limited to the field of physical education, and its practice. They learn when they behave in a responsible way in all areas that can help others to learn better.

Most children need a long time to develop personal and social responsibility, although some may reach levels of responsibility quickly. Therefore, when the model of social skills related to the learning-teaching of the personal and social responsibility is taught, is important that teachers develop lesson plans carefully considering the time required for each level and the specific activities that meet the needs of the children's development. The levels of responsibility should be taught at the beginning of the kindergarten period in order to prepare children to behave responsibly when interacting with peers and teacher. The time needed to teach the model of social skills related to learning-teaching personal and social responsibility may vary from one semester to one year, 
depending on when the children reach the levels of responsibility. Hellison (2003) uses meeting groups while developing the lesson and in the warm-down period to conceptualize the meaning of teaching strategies through the proposed activities. The class format is developed through the following steps:

1. Introductory lesson. The levels of social skills related to learning and teaching of personal and social responsibility are introduced and reviewed by performing simple warm-up activities that enable children to understand and practice the behaviours of each level.

2. Physical activities. Appropriated to the development of the physical movement and activities like games related to specific social skills so that children can practice responsible behaviour and motor skills.

3. Evaluation. In this step, the behaviours are shown during the physical education session and in the classroom.

\section{Discussion and Conclusions}

Teachers should emphasize specific behaviours of each level along their lessons, and physical activities and games should incorporate variations to keep the attention of children. Children develop motor and social skills through play, as the game offers many opportunities to integrate their interactive social behaviours (e.g. cooperating, helping, sharing and respect) in order to get along with others and develop competencies in basic motor skills. Getting along with others is fundamental for children to play socially and develop better friendships with peers. Furthermore, good friendships provide emotional support to children, allowing them to solve problems together and learn new skills from others. Many authors believe that children with good relationships with their peers find it easier to adapt to the school environment and have better academic performance in general.

Certainly, from the perspective of the development of motor skills, basic abilities or motor patterns (catch, grasp, release, crawl, roll, walk, jump, run, climb, descend, manipulate, handle the body in different spaces, etc) are extremely important as they are the ABCs of movement to promote the future learning and development of movement abilities of young children. Several studies about motor development show that getting basic motor skills during early childhood is critical to future participation in sports, games and physical activities.

Children are able to learn to be responsible for their own actions if these behaviours are systematically taught at an early age. The task described in the text give some ideas how to teach children that they can learn to be responsible for their own actions. As these behaviours we have to be able to systematically teach them at an early age. The instructions described in the text, give some ideas of how to teach every level of social skills behaviours related to learning by applying a model of teaching personal and social responsibility modified in the field of Physical Education.

Teachers should emphasize specific behaviours of each level along their lessons, and the physical activities and games should be varied to keep the attention of kids. By systematically practicing these behaviours are reinforced, children will learn personally and socially responsible behaviours that certainly will help them throughout their school life. So we can conclude stating that: social skills are important for a good future development of the child, in any type of activity that the child develops in class uses social skills and therefore should handle them, some students with shyness or too impulsive, have to learn to control these impulse skills. These abilities allow the child apart from having a better social adjustment, increase knowledge of him, improve his emotional expression, improve conflict resolution and empathize better with others.

\section{References}

[1] National Association for Sport and Physical Education (2002) Active start: A statement of physical activity guidelines for children brith to five years. Reston, VA: Author.

[2] Clark, J. E. y Metcalf, J. S. (2002) The mountain of motor development: A metaphor. In J. E. Clark \&J.H. Humphrey (Eds) Motor development: Reserch and reviews, volume 2 (pp. 163-190). Reston, VA: National Associotion for Sport and Physical Education.

[3] Gil Madrona, P. y col. (2008) "Habilidades motrices en la infancia y su desarrollo desde una educación física animada". Revista Iberoamérica de Educación, nº 47. Pp. 71-97. OEI. Madrid.

[4] McWayne, C.M., Fantuzzo, J.W. \&McDermott, P.A.(2004). Preschool competency in context: An investigation of the unique contribution of child competences to early academic success. Developmental Psychology, 40 (4), 633-645.

[5] McClelland, M.M. \& Morrison, F.J. (2003). The emergence of learning-related social skills in preschool children.Early Childhood Research Quarterly, 18 (2), 206-224.

[6] Cooper, D.H., \&Farran, D.C. (1991). The CooperFarran Behavioral Rating Scales. Brandon, VT: Clinical Psychology Publishing Co., Inc.

[7] Rairigh, R. M., \& Townsend, J. S. (2001). Moving beyond the why: How to integrate into physical education. Teaching Elementary Physical Education, 12, 34-37.

[8] Hellison, D. (2003). Teaching Responsibility Through Physical Activity (2nd ed.) Champaign, IL: \Human. 